\title{
Os direitos de propriedade intelectual como estratégia de libertação do Japão da dependência econômica dos Estados Unidos no pós-guerra do Século XIX
}

\author{
Intellectual property rights as a release strategy for Japan from \\ the economic dependence of the United States in the post war \\ of the 19th century
}

Guilherme Aparecido da Silva Maia

Universidade Anhanguera - Uniderp

RoSEMARY MATIAS

Universidade Anhanguera - Uniderp

Ademir Kleber Morbeck de Oliveira

Universidade Anhanguera - Uniderp

RESUMO O que o Japão pode ensinar em relação à propriedade intelectual, sendo um dos países mais desenvolvidos da Ásia e do mundo? O seu processo de evolução é milenar; entretanto, ao estudá-lo e compará-lo com outros países, como a Coreia do Sul e os Estados Unidos da América, considerando o que foi exposto, o seu desenvolvimento econômico foi consolidado graças à proteção da propriedade intelectual. Desse modo, o objetivo foi compreender a estruturação da propriedade intelectual no Japão e sua relevância para sua liderança econômica mundial. A metodologia aplicada foi a revisão sistemática que ocorreu em três estágios: planejamento, condução e disseminação. Os resultados indicaram que o processo de modernização econômica ocorreu no período Meiji (1868-1912), no qual os japoneses puderam experimentar e praticar seu processo criativo sem as amarras dos acordos internacionais propostos pelas Convenções de Paris (1883) e Berna (1886) e, posteriormente, em 1994, pela Organização Mundial do Comércio, via o acordo sobre os Aspectos dos Direitos de Propriedade Intelectual Relacionados com o Comércio e da Organização Mundial do Comércio. Conclui-se que é necessário dar prioridade ao conhecimento doméstico, consolidando uma estrutura interna de proteção do conhecimento e, após, exportar os frutos dessa proteção na forma de tecnologias.

Palavras-chave: Proteção intelectual; EUA; Spillover de conhecimento; Patente. 
ABSTRACT What can Japan teach about intellectual property, being one of the most developed countries in Asia and the world? Its evolution process is millennial; however, when studying it and comparing it with other countries, such as South Korea and the United States of America, considering what was exposed, its economic development was consolidated thanks to the protection of intellectual property. Thus, the objective was to understand the structuring of intellectual property in Japan and its relevance to its global economic leadership. The methodology applied was the systematic review, which took place in three stages: planning, conducting and dissemination. The results indicated that the process of economic modernization occurred in the Meiji period (1868-1912), where the Japanese were able to experiment and practice their creative process without the constraints of the international agreements proposed by the Paris (1883) and Berne (1886) Conventions and, later, in 1994, by the World Trade Organization, it saw the agreement on Trade-Related Aspects of Intellectual Property Rights and the World Trade Organization. It is concluded that it is necessary to give priority to domestic knowledge, consolidating an internal structure of protection of knowledge and, later, to export the fruits of this protection in the form of technologies.

Keywords: Intellectual Protection; USA; Knowledge Spillover; Patent.

\section{INTRODUÇÃo}

Qual a lição que o Japão pode ensinar em relação à proteção do conhecimento? Atualmente, é um exemplo de um país desenvolvido. Porém, as etapas desse desenvolvimento nem sempre resultaram em progresso econômico imediato. O Japão percorreu um longo caminho até alcançar esse estágio de desenvolvimento. Além disso, a causalidade nem sempre é clara, e a questão permanece inevitavelmente na medida em que os direitos de propriedade intelectual promovem o progresso econômico que, consequentemente, resulta em demanda por direitos de propriedade intelectual (DREXL et al., 2009).

Desde o direito de guildas, nos séculos XVIII e XIX, até os acordos internacionais, o Japão foi palco de intensas batalhas pelo direito dos japoneses de pensar e transformar seu pensamento criativo em algo a ser protegido. O período do pós-guerra de 1945 foi o mais emblemático. Derrotados pelos EUA, o país teve de curvar-se perante a opressão tecnológica dos americanos. Porém, ao aplicar a engenharia reversa, os japoneses acabaram por apropriarem-se das tecnologias a eles impostas e consolidaram sua própria tecnologia, conquistando assim a sua independência econômica em plena época de colonização tecnológica.

Esse cenário é parecido com o da China do final do século XX, porém, o Governo do Japão adotou como estratégia de desenvolvimento tecnológico e econômico a construção de infraestrutura básica nas áreas essenciais como parques tecnológicos, transporte e incentivos governamentais para a formação e fixação de competências locais. Essa estratégia resultou na elevação dos indicadores de patentes domésticas e, consequentemente, na consolidação de um mercado internacional. Na China, embora consiga produzir com competitividade, sua estratégia não resultou em conquista de um sólido mercado internacional em áreas importantes como a automobilística, por exemplo, como aconteceu com o Japão, cujos carros ganharam o mercado mundial. A China consegue ganhar mercado às custas de produtos baratos e de baixa qualidade. O Japão já superou essa fase, por isso, conquista e mantém seu mercado pela competitividade e qualidade. 
Ao estudar os direitos de propriedade intelectual no Japão, uma nuance aparece em comum nos países que conseguiram alcançar o desenvolvimento, como é o caso da Coreia do Sul. Assim como também no Japão, na Coréia do Sul, o número de patentes de propriedade nacional supera o número de patentes de propriedade estrangeira. Essa relação de causa e efeito nem sempre aparece em uma primeira leitura, porém, ela faz toda a diferença ao analisar-se o contexto do desenvolvimento desses países (DREXL et al., 2009).

Ao comparar-se os indicadores de transbordo do conhecimento (spillover), será constatado que, em determinado momento da história, os japoneses iniciaram sua trajetória de exportadores do conhecimento e não mais como importadores, como havia experimentado em épocas de dominação tecnológica americana.

Desse modo, este artigo tem como objetivo o estudo e a compreensão da importância da propriedade intelectual no Japão e como esse país consolidou sua estrutura de proteção do conhecimento, cujo resultado foi o desenvolvimento econômico, permitindo suprir uma lacuna na investigação acadêmica, pois, relacionar a proteção do conhecimento ao desenvolvimento de um país nem sempre tem sido a prioridade nos estudos acadêmicos.

A metodologia adotada foi a de Revisão Sistemática, a qual ocorreu em três estágios: planejamento, condução e disseminação, conforme TRANFIELD et al. (2003), adaptado de CLARK e OXMAN (2001).

$\mathrm{Na}$ etapa 1 (planejamento), foram identificadas as necessidades do estudo e desenvolvimento de protocolo, desenvolvido a partir das seguintes questões norteadoras: como está estruturado o direito de propriedade intelectual no Japão? Quais são as estruturas de proteção da propriedade intelectual? Qual o papel da propriedade intelectual no desenvolvimento do País?

Nessa etapa, a estratégia de busca foi adaptada de Silva (2016) (Quadro 1).

$\mathrm{Na}$ etapa 2 (condução), foram prospectadas, identificados, selecionados e executadas as buscas, objeto da revisão sistemática, por meio dos portais de busca Scielo, CAPES e Google Acadêmico. Na estratégia de busca, itens 1, 2 e 3, as palavras-chave utilizadas foram na Língua Portuguesa e direcionadas às publicações nacionais e, nos itens 4, 5 e 6, em Inglês. O critério de seleção foi o de relevância (qualis para os artigos e visibilidade para os livros).

Quadro 1. Estratégia de busca das publicações com foco em propriedade intelectual e direitos de autor

\begin{tabular}{|c|l|}
\hline Estratégias de Busca & Palavras-chave e combinação de termos \\
\hline Busca 01 & Proteção do conhecimento, propriedade intelectual, Japão \\
\hline Busca 02 & Convenções internacionais, propriedade intelectual, Japão \\
\hline Busca 03 & Direitos de autor, propriedade intelectual, Japão, PIB \\
\hline Busca 04 & Copyrights and Intellectual Property, Japan \\
\hline Busca 05 & Intellectual Property in Japan, development \\
\hline Busca 06 & Intellectual Property and Japan, GDP \\
\hline Busca 07 & Copyrights and Intellectual Property in Japan \\
\hline
\end{tabular}

Fonte: Adaptado de Silva (2016). 
$\mathrm{Na}$ etapa 3 (disseminação), as obras foram divididas em grupos temáticos (assunto e localização geográfica) e identificadas as contribuições de cada autor de acordo com o campo pesquisado. Os elementos legislativos foram analisados e combinados com elementos econômicos disponibilizados pelo portal da World Intellectual Property Organization (WIPO).

O trabalho de busca de publicações resultou nas obras que embasam este trabalho, listadas ao final (Referências) e a análise completa está neste artigo.

\section{Aspectos legislativos e CUlturais da PROPRIEDAde INTEleCtUal do JAPÃO E SUA INFLUÊNCIA NO DESENVOLVIMENTO ECONÔMICO}

Segundo Nagaoka (2009), a história da propriedade intelectual japonesa começou logo após a Restauração Meiji de 1868. Anteriormente a este período, o que existia era uma sociedade de castas feudais, estritamente separada em cavaleiros samurais, camponeses e, no nível mais baixo da hierarquia, artesãos e comerciantes. A criatividade individual não era muito apreciada e a filosofia do estado era o neoconfucionismo, uma escola de pensamento que favoreceu a subordinação à comunidade sobre a autorrealização individual em termos de criatividade e inovação. Em 1718, o governo até promulgou uma lei que proibia a inovação.

Porém, foi na classe de artesãos e comerciantes, a mais baixa, que começou a ocorrer a criação de atividades literárias e artísticas. Ao contrário do Samurai estoico, que desprezava todos os tipos de sentimentos externos como a paixão, a luxúria e demais emoções, eles desenvolveram formas de arte altamente alegres, frívolas, como o teatro Kabuki e pinturas que refletiam o sentimento de um mundo fugaz, tal como o ukiyo, um gênero de xilogravura e pintura que prosperou entre os séculos XVII e XIX (JPO, 2018).

Em 1853, os EUA atacaram Edo Bay (Tóquio). Desde então, tanto os Estados Unidos quanto a Europa pressionavam o país a abrir seus portos para o comércio exterior e a assinar os chamados tratados comerciais desiguais. Os tratados previam, entre outras coisas, condições comerciais irreparáveis e a não aplicação da lei japonesa aos residentes de nacionalidade estrangeira. Um grupo de samurais progressistas reconheceu a incapacidade do regime de evitar o avanço da colonização. Teve início então a Restauração Meiji, que visava a retomada do papel do imperador, que havia desaparecido da cena desde o século XII (o fim do regime de Kamakura). Esse foi o início de um enorme esforço para reconstruir o Japão em uma nação econômica e militarmente poderosa. A autorrealização individual em termos de criatividade e inovação começou a desempenhar um papel importante no desenvolvimento posterior (NAGAOKA, 2009).

No período de 1868 a 1880 aconteceu no Japão a denominada reforma legal, impulsionada tanto pelo desejo de se livrar dos humilhantes tratados comerciais desiguais quanto pelo alcance do Ocidente. A introdução da proteção da propriedade intelectual foi percebida como uma ferramenta útil para promover a industrialização. Antes dos padrões de proteção internacional não existirem, os europeus e americanos divulgaram com orgulho seus conhecimentos avançados e invenções para os asiáticos, evidenciando seu atraso como nação (NAGAOKA, 2009; JPO, 2018).

A partir da restauração $M e i j i$, a propriedade intelectual tinha tanto valor que o imperador instituiu o dia 18 de abril de 1885 como o Patent Monopoly Act (Dia da Inovação). A 
partir desse ano, todos os anos da Era Meiji comemoravam esse como sendo um marco da estratégia de inovação desse importante imperador (JPO, 2018).

Em comparação com os países em desenvolvimento de hoje, o Japão estava em uma posição única. Por um lado, gozava da liberdade de absolver conhecimentos estrangeiros por meio de traduções de livros científicos sem pedir permissão aos autores ou por meio de cópia de máquinas sem sequer pagar uma taxa; e, por outro lado, poderia testar o efeito de patentes, direitos autorais e marcas registradas sobre o desenvolvimento tecnológico e econômico dentro de um contexto puramente doméstico (NAGAOKA, 2009).

Para Heath (2005), esse ambiente favorável, aliado à curiosidade natural dos japoneses possibilitaram a descoberta de novas tecnologias, principalmente as armas vindas de outros países e que despertavam tanto a curiosidade desse povo. $\mathrm{O}$ autor cita como exemplos os casos dos navios estrangeiros que chegavam ao Japão nos anos 1852 e os oficiais japoneses que tinham curiosidade em saber como as armas funcionavam, seu manuseio e como eram fabricadas. Perguntavam, anotavam e ouviam tudo com muita atenção.

A curiosidade sobre a propriedade intelectual, não só como instrumento bélico, mas também como instrumento de desenvolvimento econômico foi rapidamente percebida nessa época e, também, a posteriori, nas viagens que os estudiosos realizaram aos EUA. A forma da propriedade intelectual, em especial do sistema de patentes, é destacada por uma afirmação retrospectiva frequentemente citada dada por Korekiyo Takahashi, o primeiro presidente do Escritório de Patentes Japonês, em sua autobiografia em 1900:

\footnotetext{
Examinamos a nossa volta para ver quais são as nações melhores, para que possamos ser como eles. Nós dissemos: O que é o que faz dos Estados Unidos uma grande nação? E investigamos e descobrimos que eram patentes, então teremos patentes $^{1}$ (HEATH, 2005 apud NAGAOKA, 2009, p. 129).
}

Pouco depois de Meiji, foram promulgadas as primeiras normas sobre patentes, direitos autorais, design e proteção de marca registrada. Na década de 1880, depois de um período de regras deficientes e falta de recursos para sua administração, as leis de propriedade intelectual foram se tornando realmente instrumentos aplicáveis. Especificamente, em 1887, as primeiras ordenanças foram transformadas nas primeiras regras de direitos autorais reais na medida em que foram separadas das disposições sobre censura e controle de publicação (HEATH, 2005).

Quanto às patentes, inicialmente, a legislação abrangia apenas as invenções domésticas, enquanto a tecnologia importada permaneceu livremente explorável. Em 1885, a Portaria de Patentes de Venda exclusiva foi promulgada, tornando assim a primeira disposição de patente realmente aplicável. Desse modo, passou a valer a norma que exigia que os pedidos de patente deveriam incluir uma descrição do pedido de proteção, que deveria ser submetido ao Ministério da Agricultura e Comércio (o antecessor do Ministério do Comércio Internacional e da Indústria). O fato de a legislação de propriedade industrial ter sido preparada pelo Ministério da Indústria e do Comércio denota sua vocação industrial. A regulamentação continha regras detalhadas sobre os pré-requisitos de proteção, marcação de patentes e sanções crimi-

Traduzido do original. 
nais, mas permaneceu defeituosa em vários aspectos. Por exemplo, não esclareceu a data a partir da qual o termo de proteção deveria começar (NAGAOKA, 2009).

Em 1888, uma nova Portaria de Patentes substituiu as disposições de 1885. Devido ao retorno do Korekiyo Takahashi (um dos muitos japoneses que viajaram aos EUA em busca de conhecimentos), a Portaria de Patentes foi fortemente influenciada pelos princípios dos EUA. Um exemplo dessa influência foi a adoção do Princípio do Primeiro a Inventar. Os japoneses, no entanto, ainda fizeram pouco uso do instrumento jurídico de proteção. Nos primeiros anos após 1885, o número médio de patentes concedidas a cada ano era inferior a 250 (HEATH, 2005).

Em relação às marcas registradas, o primeiro documento regulador consta de 1884 , mas logo foi substituído por uma Portaria governamental de 1888 que, entre outras coisas, esclareceu o pré-requisito de distinção. De acordo com a Lei, as marcas registradas só podem ser transferidas em conjunto com a totalidade do negócio, e o período de cancelamento de não uso foi de seis meses. Após vários projetos improvisados, um Projeto Lei foi finalmente promulgado em 1888. A proteção legal dos projetos era urgentemente necessária porque a pirataria de produtos se tornara desenfreada (NAGAOKA, 2009).

A proteção de desenho industrial foi caracterizada pelo Princípio do Primeiro Ato, exame substantivo quanto à novidade e à obrigação de indicar o direito de projeto sobre o produto. A violação foi uma questão de processo penal. Além disso, foi dada ênfase especial ao Princípio do Serviço, ou seja, a propriedade dos projetos feitos pelos funcionários foi anexada aos empregadores. É notável que o princípio do serviço não tenha sido introduzido na lei de patentes até 1909. Aparentemente, o atraso foi causado pelo fato de que os principais candidatos à proteção de patentes ainda eram inventores individuais. No que diz respeito aos artigos de design, no entanto, a relação mestre-aprendiz em guildas de artesanato caracterizava-se como uma relação empregado-empregador, tradição herdada da pré Era Meiji, do século XIX, caracterizado como um período de experimentação em que os japoneses testaram vários modelos de legislação para encontrar o que melhor se adequava à realidade econômica (NAGAOKA, 2009).

Como não havia demandas para proteger a propriedade intelectual estrangeira, esse processo de tentativa e erro foi fundamentado em uma atitude positiva em relação a patentes, projetos, marcas registradas e direitos autorais. Nessa fase inicial, no entanto, a propriedade intelectual ainda era percebida como um instrumento para fomentar a criatividade de inventores e criadores individuais do que como uma ferramenta para garantir o investimento corporativo. A disponibilidade de patentes, em particular, contribuiu para o surgimento de uma classe única de inventor-empreendedor com invenções que se encaixam em um ambiente econômico ainda caracterizado por agricultura e artesanato (NAGAOKA, 2009).

No Japão, até o início do século XX, o foco era a proteção dos direitos internos de propriedade intelectual. Foi a partir da década de 1880, com o surgimento dos primeiros acordos frutos das convenções multilaterais de proteção da propriedade intelectual, nomeadamente a Convenção de Paris, em 1883, e a Convenção de Berna, em 1886, que os titulares de direitos de propriedade estrangeiros reconheceram o Japão como um mercado cada vez mais rico com uma forte demanda, não apenas pelo conhecimento técnico, mas também por livros e música. Na década de 1890, o Japão foi atraído para uma série de acordos bilaterais 
que permitiram que os estrangeiros apresentassem patentes no Japão ou obrigassem a se tornar membros das novas convenções de propriedade intelectual (NAGAOKA, 2009).

As exigências para aderir à Convenção de Berna causaram muita comoção interna, porque a tradução de livros científicos estrangeiros ainda era o principal canal de importação de conhecimento internacional. Muitos japoneses temiam que a importação de conhecimento minasse seu mercado de trabalho se os estrangeiros pudessem exercer seus direitos autorais no Japão. Entretanto, os tratados comerciais desiguais, anteriormente mencionados, ainda estavam em vigor e os EUA e os europeus tornaram a adesão do Japão à Convenção de Berna e de Paris uma condição prévia para a abolição desses tratados. Essas adesões se deram em 1899, para ambas as Convenções. Houve necessidade de adequações do sistema de proteção intelectual japonês para a adequação aos requisitos mínimos de ambas as convenções (NAGAOKA, 2009).

No campo da propriedade industrial, especialmente as patentes, a imposição de obrigações internacionais, notadamente, Convenção de Paris, não destruiu a atitude positiva em relação à propriedade intelectual. Em 1905, a primeira Lei do Modelo de Utilidade foi promulgada, embora essa proteção não fosse exigida pelos tratados internacionais de propriedade intelectual. O objetivo era reservar modelos de utilidade para inventores japoneses, uma vez que os mesmos pensavam que, após a adesão à Convenção de Paris, a grande maioria das patentes de inovações seria concedida aos estrangeiros. O modelo de estrutura legislativa foi o da Alemanha, onde essa proteção já existia desde 1891 (NAGAOKA, 2009).

A proteção do modelo de utilidade em invenções menores também se encaixava no cenário industrial contemporâneo, no qual as grandes empresas com sólidas capacidades de pesquisa e desenvolvimento (P\&D) ainda eram raras. A lei japonesa, ao contrário da alemã, foi regida pelo Princípio do Primeiro Pedido. A proteção do modelo de utilidade exigia um menor grau de inventividade, e a novidade era limitada a doméstica. O tema da proteção incluiu desenvolvimentos úteis sobre a forma, o arranjo ou o conceito de um objeto comercial. O prazo de proteção foi limitado a seis anos a partir da aplicação. Ao contrário da Alemanha, os aplicativos do Modelo de Utilidade foram examinados substancialmente. A prática de aplicação mostra que os japoneses fizeram bom uso do novo instrumento de proteção. De 1906 a 1910, a taxa de aplicação aumentou de 2.011 para 14.057. Na década de 1930, as aplicações excederam 30.000 por ano (NAGAOKA, 2009).

O temor que, após a adesão à Convenção de Paris, os estrangeiros se tornassem os principais usuários do sistema de patentes, aumentando a atividade nacional de patentes, não se concretizou. Pelo contrário. Essa reação teria correspondido ao padrão de resposta negativa encontrado por Lerner (2002) na avaliação do efeito das mudanças de política na atividade de patenteamento nacional.

$\mathrm{O}$ número de pedidos de patentes nacionais continuou a aumentar em $6 \%$ ao ano. Atualmente, cerca de $90 \%$ dos subsídios são para os candidatos domésticos. É importante ressaltar que, mesmo no período inicial após a adesão do Japão à Convenção de Paris em 1899, a participação doméstica permaneceu elevada. Outro fato relevante que merece atenção é que, mesmo com o aumento crescente de patentes nacionais (domésticas), o Japão não diminuiu os investimentos em pesquisa. Devido à demanda específica e sua baixa 
renda per capita, talvez não tenha havido muita necessidade de inovações estrangeiras e o incentivo para que outros apresentassem pedidos de patentes no Japão poderia ter sido correspondentemente baixo (NAGAOKA, 2009).

O fim da Primeira Guerra Mundial marcou o início de um boom econômico que logo exigiu uma revisão das leis de propriedade industrial existentes. Em 1921, as leis que regem as patentes, os modelos de utilidade, os desenhos e as marcas registradas foram modificados de forma correspondente.

No campo das patentes, a introdução de regras sobre os inventos dos empregados previa que as empresas, em vez de inventores individuais, em breve se tornassem a principal fonte de inovação. Houve também alterações da Lei do Modelo de Utilidade do mesmo ano, com o objetivo de melhor definir a diferença entre um modelo de utilidade e uma patente. As emendas de 1921 à Lei de Desenho Industrial esclareceram que a proteção só deveria estar disponível para a concepção de um artigo e, portanto, não para meras decorações que poderiam ser anexadas a outros artigos. As alterações à Lei de Marcas, de 1921, prolongaram a proteção contra a marcação não autorizada de produtos idênticos para incluir também produtos similares (NAGAOKA, 2009).

No início do século XX, o Japão foi confrontado por estrangeiros que exigiam uma Lei de Concorrência Desleal. O debate estava centrado na rotulagem dos produtos praticada pelos japoneses. Eles fabricavam os produtos e colocavam na etiqueta que eram fabricados no exterior. Isso valorizava os produtos, visto que, naquela época, o país não tinha prestígio internacional como tem nos dias atuais. Além disso, as preocupações com a proteção do consumidor foram poucas. Não havia por parte dos consumidores uma investigação sobre a veracidade das informações dos rótulos dos produtos japoneses. Desse modo, o governo apoiou abertamente a rotulagem enganosa potencializando, assim, a concorrência desleal sob o argumento de que a exportação de produtos sofreria se eles fossem rotulados corretamente (NAGAOKA, 2009).

Como um membro para a Convenção de Paris, no entanto, o Japão não podia ignorar os tratados internacionais de concorrência desleal, especialmente a Conferência de Washington de 1925 que introduziu um padrão mínimo de proteção. Em 1934, o Ato de Concorrência Desleal foi finalmente promulgado. Consistia apenas em seis disposições que proibiam o uso de nomes de fabricantes amplamente conhecidos, o uso de nomes comerciais de mercadorias de forma confusa ou para prejudicar a reputação de outros fabricantes e o uso de símbolos oficiais como bandeiras. Apesar dessa promulgação, é evidente que as regras não foram realmente colocadas em prática pelas indústrias japonesas. Embora os EUA tenham abolido algumas deficiências da legislação de concorrência desleal, após a ocupação de 1945, a concorrência desleal foi praticada até a década de 1960. No entanto, até a década de 1990, todas as alterações da pós-guerra foram feitas para acomodar interesses estrangeiros, principalmente dos EUA (NAGAOKA, 2009).

Ao analisar a história da propriedade intelectual no Japão, é fundamental esclarecer que, foi a partir de 1945, com o advento da Segunda Guerra Mundial, que os japoneses puderam compreender que uma coisa era compreender a tecnologia ocidental e outra coisa, bem diferente, era produzi-la, em nível internacional e competitivo. Os esforços das décadas seguintes, portanto, concentraram-se no estabelecimento de uma base industrial está- 
vel e internacionalmente competitiva. Um dos novos slogans foi gyôsei shidô (orientação administrativa), coordenado pelo novo Ministério do Comércio Internacional e Indústria (MITI, hoje, METI Ministério da Economia, Comércio e Indústria). Contrariamente a uma economia de comando socialista, esse modelo administrativo era velado, vez que as empresas foram recomendadas a não demonstrarem abertamente sua política industrial (TAPLIN, 2014; HEATH, 2005).

Um indicador de que a maioria das empresas tenha aderido a essa orientação foi o poder do governo na alocação de trocas estrangeiras na década de 1950, até a introdução da convertibilidade do iene. Os empresários japoneses tinham a consciência de que o governo poderia atrapalhar, em muito, seus interesses econômicos e que a cooperação seria a melhor estratégia. Nas décadas seguintes, a indústria japonesa realizou um elevado número de contratos de licença de tecnologia com empresas estrangeiras e procurou melhorar seu sistema de produção, principalmente sob a filosofia budista de harmonia, cooperação e trabalho, que possibilitaram o crescimento e consolidação da indústria nacional japonesa (TAPLIN, 2014).

As estratégias de competitividade na esfera da proteção intelectual surtiram efeito. Já em 1991, o Japão possuía 24\% das patentes simultaneamente solicitadas no Instituto Europeu de Patentes (EPO - European Patent Office) e no Gabinete de Patentes Japonês (JPO Japan Patent Office) e concedidas pelo Escritório de Marcas e Patentes dos Estados Unidos (USPTO - United States Patent and Trademark Office), da família triádica (Triadic Patent Family - denominação da Organização e Cooperação para o Desenvolvimento Econômico, quando uma patente é depositada no Japão, Estados Unidos e Europa), enquanto 34\% eram contabilizadas pelos Estados Unidos e o restante foi formado pelas três principais nações europeias: França, Reino Unido e Alemanha. O índice de patentes do Japão por milhão é de 92,3 e, portanto, significativamente superior à média de 70,8 dos três principais países europeus e, 57,7 para os Estados Unidos (NAGAOKA, 2009).

Entretanto, essa estratégia japonesa nem sempre foi vista com bons olhos pelos outros países, principalmente, EUA e Alemanha, líderes mundiais em desenvolvimento tecnológico. Depois da Segunda Guerra Mundial (1939-1945), a política do governo japonês foi bastante agressiva e tendenciosa em relação aos investidores estrangeiros. Um exemplo foi o caso da IBM, forçada pelo vice-ministro do Ministério do Comércio Internacional e Indústria do Japão, em 1950, a disponibilizar suas tecnologias para as indústrias domésticas no Japão (OLWAN, 2013).

De qualquer modo, o fato é que o Japão conseguiu seu desenvolvimento econômico. Segundo Drexl et al. (2009), essa estratégia adotada teve resultados positivos na sua economia, considerando o incremento do PIB, um dos maiores da Ásia (Quadro 2). 
Quadro 2. Relação entre patente, marca e desenho industrial, em milhares, e o PIB, em milhões, do Japão no período de 2007 a 2018

\begin{tabular}{|c|c|c|r|r|}
\hline \multicolumn{5}{|c|}{ PI (Doméstica + Externa. Incluindo Regional) e Economia } \\
Ano & Patente & Marca & Desenho Industrial & PIB (Constante 2011 US\$) \\
2007 & 508.263 & 102.665 & 4.697 .29 \\
2008 & 509.990 & 107.108 & 4.645 .93 \\
2009 & 463.601 & 86.406 & 4.394 .25 \\
2010 & 468.417 & 102.977 & 4.578 .47 \\
2011 & 475.051 & & 127.795 & 4.573 .19 \\
2012 & 490.271 & & 120.761 & 4.641 .56 \\
2013 & 473.141 & 366.689 & 112.225 & 4.734 .41 \\
2014 & 465.971 & 415.927 & 112.295 & 4.750 .30 \\
2015 & 457.952 & 525.917 & 105.746 & 4.808 .23 \\
2016 & 456.467 & 622.072 & 119.141 & 4.856 .24 \\
2017 & 460.771 & 768.431 & 134.524 & 4.932 .90 \\
2018 & 460.369 & 719.264 & 141.278 & 4.971 .77 \\
\hline
\end{tabular}

Fonte: WIPO (2019).

O número de patentes domésticas concedidas aos japoneses ultrapassou o número de patentes nacionais dos EUA no início da década de 1980 permanecendo a contemporaneidade (Figuras 1 e 2). O Japão, além de incrementar a sua produção nacional de patentes, ainda possui conhecimento suficiente para spillover (abroad), demonstrando, assim, a sua liderança em propriedade intelectual (Figura 1).

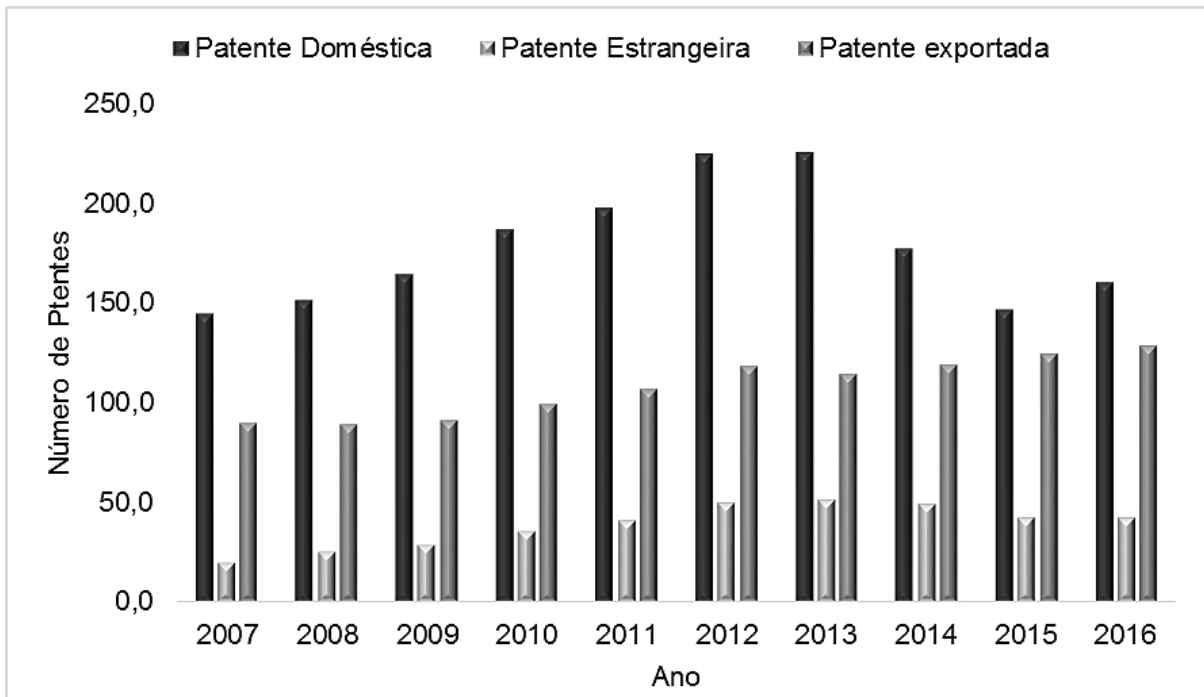

Figura 1. Número de patentes domésticas (resident), estrangeiras (non-resident) e concedidas no exterior (abroad), em milhares, pelo Japão, no período de 2007 a 2016.

Fonte: Adaptado de WIPO (2019). 
Analisando os números das patentes (Quadro 2), constata-se que em 2007, a taxa de patentes domésticas era de 0,5687 (56,9\%), as não-residentes era de 0,0780 (7,8\%) e, o spillover, era de 0,3531 (35,3\%). Essas taxas foram sofrendo pequenas alterações que podem ser percebidas na avaliação dos percentuais do ano de 2016. Nesse ano, o percentual de patentes domésticas era de 56,9\% $(0,5687)$ e caiu para $48,4 \%(0,4842)$; por outro lado, as patentes não-residentes aumentaram de 7,8\% (0,0780) para 12,8\% $(0,1279)$. Entretanto, o transbordo de conhecimento (spillover) cresceu significativamente, aumentando de $35,3 \%(0,3531)$, para 38,8\% (0,3878), comprovando assim a estratégia de exportação de conhecimento dos japoneses.

Esse elevado número de patentes domésticas indica um potencial mercado interno e aponta que a estratégia do Japão foi a de ampliar seu potencial econômico por meio das patentes (Figura 2).

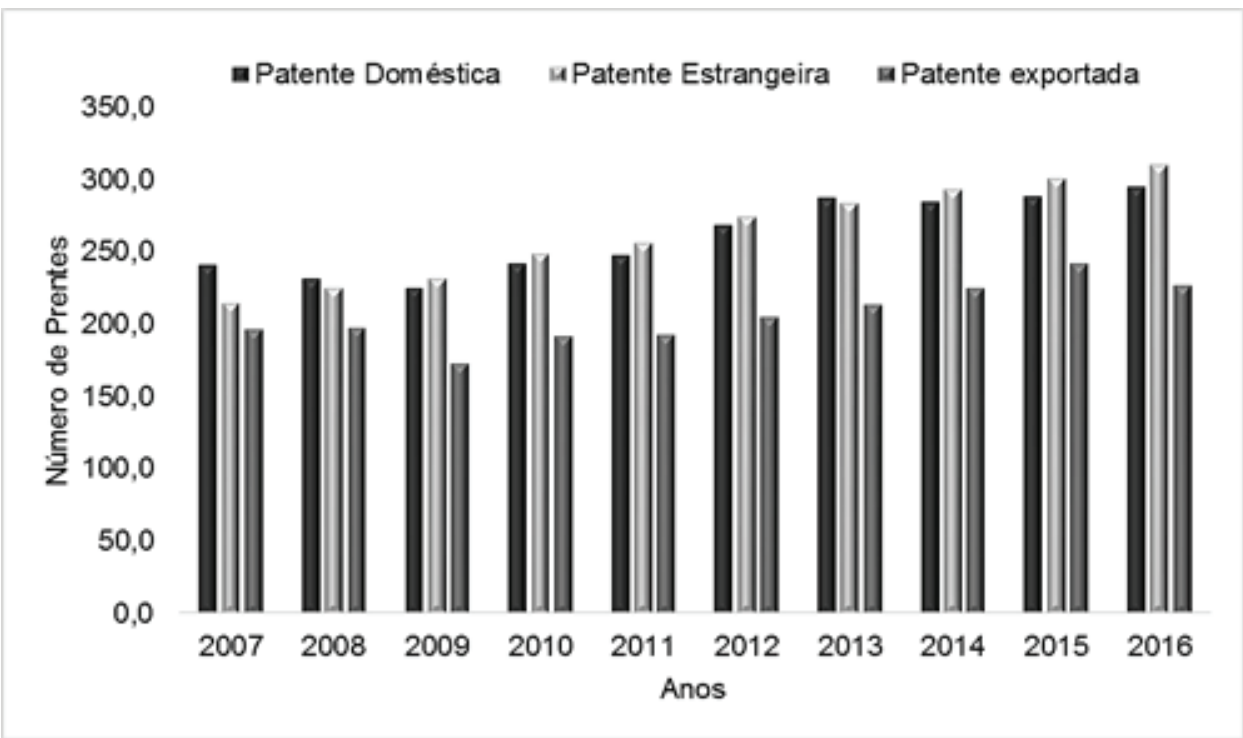

Figura 2. Número de patentes domésticas (resident), estrangeiras (non-resident) e concedidas no exterior (abroad), em milhares, pelos EUA, no período de 2007 a 2016.

Fonte: Adaptado de WIPO (2019). 
Por outro lado, a estratégia dos EUA foi consolidar seu domínio global por meio da exportação de conhecimento, evidenciado nos números significativos apontados no "abroad" do quadro 3.

Quadro 3. Aplicações das patentes domésticas (resident), externas (non-resident) e, exportadas (abroad), em milhares, do Japão no período de 2007 a 2016

\begin{tabular}{|c|c|c|c|}
\hline Ano & Doméstica & Estrangeira & Externa \\
\hline 2007 & 145,040 & 19,914 & 90,043 \\
2008 & 151,765 & 25,185 & 88,929 \\
2009 & 164,459 & 28,890 & 91,091 \\
2010 & 187,237 & 35,456 & 99,607 \\
2011 & 197,594 & 40,729 & 107,072 \\
2012 & 224,917 & 49,874 & 118,608 \\
2013 & 225,571 & 51,508 & 114,655 \\
2014 & 177,750 & 49,392 & 119,269 \\
2015 & 146,749 & 42,609 & 124,395 \\
2016 & 160,643 & 42,444 & 128,651 \\
\hline
\end{tabular}

Fonte: WIPO (2016).

Analisando o comportamento da proteção do conhecimento entre Japão e EUA, constata-se, portanto, que em 2007 o Japão tinha mais patentes (508.263) do que os EUA (437.353). Porém, em 2016, os EUA contavam com 521.802 patentes e o Japão, 456.467 patentes. Entretanto, a taxa de transbordo de tecnologias (abroad) do Japão foi maior do que a dos EUA. Em 2007 a taxa foi de 35,3\% (0,3531), enquanto a dos EUA, 30,0\% $(0,3005)$.

Em 2016, essa liderança asiática permaneceu. Enquanto os EUA detiveram 27,2\% $(0,2721)$ de spillover de conhecimento, o Japão ampliou para 38,8\% (0,3878) (Quadros 3 e 4; Figura 3).

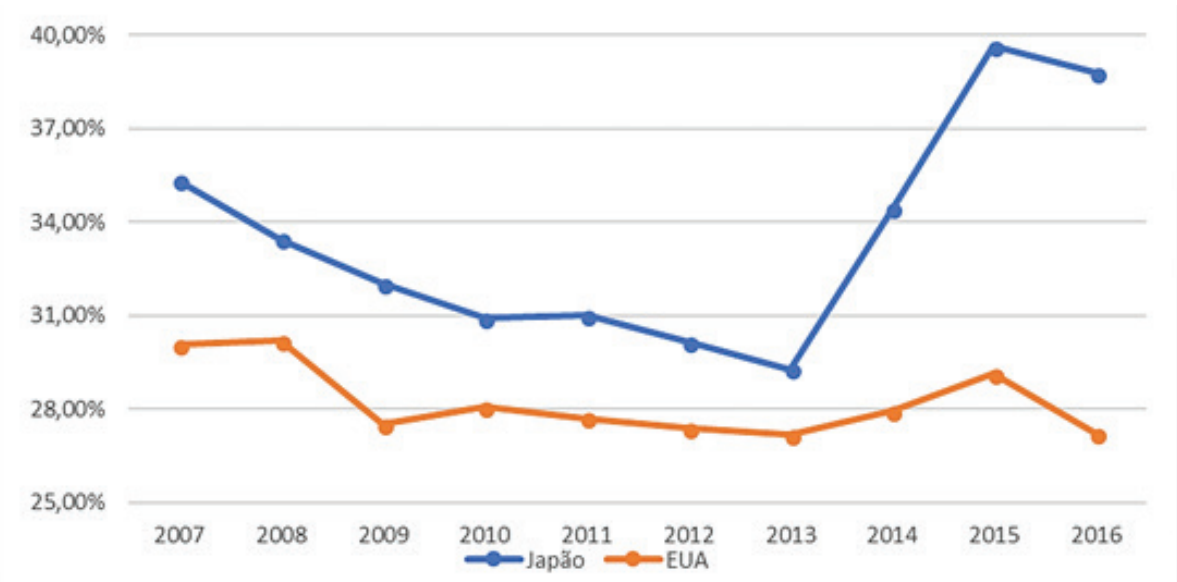

Figura 3. Spillover de conhecimento entre Japão e EUA, no período de 2007-2016.

Fonte: Elaborado pelo autor. 
A partir de 2013 o Japão iniciou sua liderança tecnológica (Figura 3) e enquanto os EUA estabilizaram seus percentuais de transbordo, a tecnologia do Japão conquistou o mundo.

$\mathrm{Na}$ avaliação entre patentes domésticas e externas, os japoneses também lideraram no período estudado (2007-2016). Enquanto os EUA tinham em 2016, 35,5\% de patentes domésticas, os japoneses detinham 48,4\%.

Segundo Nagaoka (2009), essa liderança foi se consolidando continuamente, ao longo das décadas, desde a guerra de 1945, enquanto nos EUA o número de patentes concedidas aos inventores domésticos mostrou uma diminuição da década de 1960 para o início dos anos 1980, mesmo que tenha havido um aumento substancial novamente a partir da década de 1990, conforme aponta o quadro 4.

Quadro 4. Aplicações das patentes domésticas (resident), externas (non-resident) e exportadas (abroad) dos EUA no período de 2007 a 2016

\begin{tabular}{|c|c|c|c|}
\hline ANO & DOMESTICA & ESTRANGEIRA & EXTERNA \\
\hline 2007 & 241.347 & 214.807 & 196.006 \\
2008 & 231.588 & 224.733 & 197.293 \\
2009 & 224.912 & 231.194 & 173.007 \\
2010 & 241.977 & 248.249 & 191.222 \\
2011 & 247.750 & 255.832 & 192.882 \\
2012 & 268.782 & 274.033 & 204.707 \\
2013 & 287.831 & 283.781 & 213.331 \\
2014 & 285.096 & 293.706 & 224.425 \\
2015 & 288.335 & 301.075 & 242.327 \\
2016 & 295.327 & 310.244 & 226.475 \\
\hline
\end{tabular}

Fonte: WIPO (2016).

Nesse período de 130 anos, a nação japonesa ensinou, primeiramente, que a atitude em relação à proteção intangível da propriedade era positiva desde o início. Por cerca de vinte anos após 1868, o Japão foi livre para testar a propriedade intelectual dentro de um contexto puramente doméstico. Então, no início do século XX, quando foi pressionada a se tornar um membro das Convenções de Berna e Paris, as bases para um sistema de proteção da propriedade intelectual já estavam em vigor. $\mathrm{O}$ regime internacional de propriedade intelectual, no entanto, ainda deixou espaço suficiente para adaptar as leis às necessidades nacionais, as quais se concentraram tanto em incentivos à inovação para inovadores domésticos quanto em evitar a superproteção de estrangeiros. Na mudança de imitadores para melhoradores e, finalmente, de melhoradores para inventores, o escopo de proteção e os pré-requisitos para proteção foram posteriormente aprimorados (NAGAOKA, 2009).

Mas, afinal, o que os países emergentes podem aprender com o Japão? Infelizmente, a oportunidade de testar a propriedade intelectual dentro do contexto doméstico antes de es- 
tender essa proteção aos estrangeiros definitivamente desapareceu. Os países em desenvolvimento de hoje enfrentam dificuldades de tempos contemporâneos em que imperam regras de proteção internacional as quais eles devem aderir se quiserem ter acesso em âmbito da OMC. As experiências japonesas, portanto, têm apenas uma aplicação limitada aos países asiáticos que estão agora em desenvolvimento (NAGAOKA, 2009).

Entretanto, o autor conclui que as experiências do Japão têm algo a ensinar aos demais como, por exemplo, que o desenvolvimento tecnológico após a guerra foi impulsionado por melhorias graduais feitas por especialistas e funcionários não especializados e que tanto as patentes como os modelos de utilidade constituíram ferramentas importantes para criar uma base tecnológica estável. Ao longo de décadas, essa estratégia permitiu que se tornassem produtores mundialmente conhecidos de bens de alta qualidade, mesmo que a tecnologia essencial subjacente fosse na maioria dos casos desenvolvida no exterior. Tal política de inovação, visando a inovação em pequena escala e melhorias em uma ampla base, também seria uma opção lucrativa para muitos mercados emergentes de hoje.

Desse modo, percebe-se que a estratégia do Japão foi redirecionar os milhares de engenheiros de guerra para o desenvolvimento tecnológico não bélico, em especial o eletroeletrônico e, em seguida, o setor de automóveis e motores. No início desse processo, nas décadas de 1950, os produtos japoneses tinham baixa qualidade e má reputação em outros países como os EUA e a Europa, mas os japoneses solucionaram esse problema nas décadas seguintes e ganharam mercado internacional.

Em muitos dos mercados emergentes da Ásia, acima de tudo, a China, fabricação e montagem utilizando mão de obra intensiva é a forma predominante de atividade industrial. Nesses países, no entanto, a grande maioria dos produtos exportáveis provêm do investimento direto de outros países, enquanto os produtos fabricados por empresas locais ficam muitas vezes atrasados em termos de segurança, qualidade e confiabilidade. Nada impedirá que esses países utilizem ativamente seus sistemas de modelos de patente e de utilidade e as flexibilidades remanescentes no Quadro de Convenções Multilaterais para promover a atividade inovadora em pequena escala em círculos de qualidade e similares, como fizeram os japoneses, para estabelecer uma base industrial doméstica estável.

Nesse contexto, a exceção é a Coreia do Sul, a qual tem investido na proteção doméstica como vantagem competitiva. Dados da WIPO (2016) apontam para essa realidade (Quadro 5). No período estudado, o número de patentes domésticas esteve em constante crescimento, assim como também o spillover de conhecimento (abroad).

Em 2007, das 220.104 patentes do país, 58,5\% eram domésticas e apenas 19,9\% de origem estrangeira. Se compararmos os indicadores, o número de exportação de conhecimento (spillover) foi sempre superior ao número de importação, ou seja, 19,9\% de não-domésticas contra 21,64 de abroad, em 2007. 
Quadro 5. Aplicações das patentes domésticas (resident), externas (non-resident) e exportadas (abroad) da Coreia do Sul, no período de 2007 a 2016

\begin{tabular}{|c|c|c|c|}
\hline ANO & DOMÉSTICA & ESTRANGEIRA & EXTERNA \\
\hline 2007 & 128.701 & 43.768 & 47.635 \\
2008 & 127.114 & 43.518 & 46.382 \\
2009 & 127.316 & 36.207 & 42.917 \\
2010 & 131.805 & 38.296 & 46.849 \\
2011 & 138.034 & 40.890 & 49.713 \\
2012 & 148.136 & 40.779 & 55.700 \\
2013 & 159.978 & 44.611 & 63.549 \\
2014 & 164.073 & 46.219 & 66.480 \\
2015 & 167.275 & 46.419 & 70.910 \\
2016 & 163.424 & 45.406 & 70.362 \\
\hline
\end{tabular}

Fonte: WIPO (2016).

Esses indicadores continuaram positivos em todo o período estudado. Em 2016, das 279.192 patentes, $58,5 \%$ eram domésticas, contra $16,3 \%$ de estrangeiras e a taxa de exportação continuou superior, $25,2 \%$.

Percebe-se, na Coreia do Sul, uma correlação linear positiva entre PIB e patentes. Isso quer dizer que o comportamento é linear, em 31,89\% e 30,59\%, no período de 2008 a 2017, ou seja, quando um cresce, automaticamente puxa o outro. Esse avanço tecnológico foi desencadeado pelo setor público coreano, tendo como marco histórico a criação do Instituto de Ciência e Tecnologia da Coreia (KIST), centro técnico multidisciplinar que abrigou os engenheiros vindos do setor público e colocados à disposição do setor privado.

Aliados a essa estratégia deu certo e o governo coreano criou outros centros de pesquisa autônomos ligados ao KIST. Os centros foram divididos por áreas prioritárias como construção naval, eletrônica, telecomunicações, energia, maquinaria, etc. (KIM, 2005).

\section{CONSIDERAÇÕES FINAIS}

Ao estudar-se a proteção do conhecimento no Japão, pode-se concluir que a diferença entre essa nação e os demais países da Ásia foi a atitude positiva em relação à proteção do conhecimento no período Meiji, de 1868-1912, em que o país foi livre para testar a propriedade intelectual dentro de um contexto exclusivamente doméstico.

Desse modo, quando, no início do século XX, o País foi pressionado pela OMC a se tornar membro dos tratados internacionais, notadamente WIPO (Berna e Paris), já havia consolidado seu conhecimento interno.

Mesmo com a pressão dos EUA, no período do pós-guerra, 1945, o Japão não limitou sua capacidade inventiva e inovadora. Enquanto muitos países da Ásia e mesmo da América Latina se curvaram à dominação econômica, os japoneses, em uma atitude nacionalista e preparada para suportar os imensos desafios de uma colonização tecnológica, seguiu em 
frente, rumo ao seu pleno desenvolvimento. A diferença foi seu posicionamento em relação à dominação dos países desenvolvidos da América e da Europa. Não se deixar dominar pelo conhecimento estrangeiro é uma lição que os japoneses têm a ensinar.

O Japão ensinou ao mundo que a proteção dos Direitos de Propriedade Intelectual é uma estratégia que deve ser priorizada tanto pelo Poder Público, como também pelo Poder Privado. O País investiu em produção e proteção do conhecimento como estratégia de libertação econômica, tendo como base a premissa de que o conhecimento e sua fixação em território nacional é uma questão de Soberania Nacional.

\section{REFERÊNCIAS}

CLARK, Mike; OXMAN, Andy. Cochrane Reviewers Handbook. Oxford: The Cochrane Library, 2001. 672p.

DREXL, J.; HILTY, R. M.; SCHÖN W.; STRAUS, J. Intellectual Property in Asia: Law, Economics, History and Politics. 1ed. Stanfort: Springer, 2009. 376p.

HEATH, C. Intellectual Property and Anti-Trust. In: RÖHL Wilhelm. History of Law in Japan Since 1868. Boston: Brill, 2005. p. 402-523.

JPO. JAPAN PATENT OFFICE. History of Industrial Property Rights. Japan: JPO. Tokyo, 2018. [online]. Disponível em: <https://www.jpo.go.jp/seido_e/rekishi_e/hatsumeie.htm>. Acesso em: 15 jun. 2019.

KIM, L. Da imitação à inovação: a dinâmica do aprendizado tecnológico da Coréia. 1ed. Campinas: Editora da UNICAMP, 2005. 392p.

LERNER, J. Patent Protection and Innovation over 150 Years - NBER Working Paper Series n. 987. Cambridge: National Bureau of Economic Research, 2002. 40p.

NAGAOKA, S.; GANEA, P. Japan. In: DREXL, Josef; HILTY, R. M.; SCHÖN W.; STRAUS, J. Intellectual Propery in Asia: Law, Economics, History and Politics. 1ed. Stanfort: Springer, 2009. p.129-153.

OLWAN, R. M. Intellectual Property and Development: Theory and Practice. New York: Springer, 2013. 403p.

SILVA, L. C. S. Modelo de Transferência de Tecnologia Verde por Intermédio dos Núcleos de Inovação Tecnológica em Institutos de Ciência e Tecnologia Brasileiros. 2016. 146f. Tese (Doutorado em Engenharia de Produção) - Escola de Engenharia, Universidade Federal do Rio Grande do Sul, Porto Alegre. 
TAPLIN, Ruth. Intellectual Property Valuation and Innovation: Towards Global Harmonisation. New York: Routledge, 2014. 180p.

TRANFIELD, David; DENYER, David.; SMART, Palminder. Towards a methodology for developing evidence-informed management knowledge by means of systematic review. British Journal of Management, London, v. 14, n. 3, p. 207-222, 2003.

WIPO. WORLD INTELLECTUAL PROPERTY ORGANIZATION. Statistical Country Profiles. Geneva, 2016. [online]. Disponível em: $<$ http://www.wipo.int/ipstats/en/statistics/country_profile/profile.jsp?code=KH>. Acesso em: 08 mai. 2019.

WIPO. WORLD INTELLECTUAL PROPERTY ORGANIZATION. Statistical Country Profiles. Geneva, 2019. [online]. Disponível em: $<$ http://www.wipo.int/ipstats/en/statistics/country_profile/profile.jsp?code=KH>. Acesso em: 03 out. 2019.

Guilherme Aparecido da Silva Maia

Graduado em Direito, especialista em Inovação e Difusão de Tecnologias. Mestre e doutor em Meio Ambiente e Desenvolvimento Regional. E-mail: professorguilhermemaia@ gmail.com

\section{Rosemary Matias}

Graduação em Licenciatura Plena em Química pela Universidade Federal de Mato Grosso do Sul. Doutora e mestre em Química pela Universidade Estadual de Maringá - UEM. E-mail: rosematiasc@gmail.com

\section{Ademir Kleber Morbeck de Oliveira}

Graduado em Ciências Biológicas pela Universidade Federal de Mato Grosso do Sul. Mestre em Ecologia e Recursos Naturais pela Universidade Federal de São Carlos. Doutor em Ciências, área de concentração em Ecologia e Recursos Naturais pela Universidade Federal de São Carlos. E-mail: akmorbeckoliveira@gmail.com

Submetido em: 3-11-2020

Aceito em: 26-3-2021 